\title{
САМОКОНТРОЛЬ И САМООЦЕНКА КАК СОСТАВЛЯЮЩИЕ САМООРГАНИЗАЦИИ В СОВРЕМЕННОМ УЧЕБНОМ ПРОЦЕССЕ
}

\section{SELF-CONTROL AND \\ SELF-ASSESSMENT AS THE COMPONENTS OF SELF-ORGANIZED ACTIVITY IN THE CONTEMPORARY LEARNING PROCESS \\ L. Fedko \\ O. Taranenko \\ E. Shchepoteva}

Summary: One of the tasks of training a future specialist in higher education is the formation of an active, self-organized person. The significance of self-control and self-assessment, as components of self-organization of students' educational activities in the Engineering School of the Far Eastern Federal University, was analyzed. The authors studied the level of self-assessment of the educational activities of students and its correlation with the assessment given by the instructor or classmates, the students' attitude towards the pedagogical evaluation, the correspondence of the results of educational activities to the students' capabilities, and self-assessment motives.

It was concluded, that creating conditions for students to become independent, equipping them with rational methods of mastering knowledge, actions of self-control and self-evaluation, criteria for assessing knowledge and skills, will effectively influence the development of students' self-organizational skills and enhance their learning activities.

Keywords: higher school, academic activity, learning process, personality, self-organization, self-control, self-assessment, estimate of the teacher.
Федько Людмила Александровна

К.n.н., дочент, Дальневосточный федеральный университет (Владивосток)

fedko.la@dvfu.ru

Тараненко Ольга Ивановна

Доцент, Дальневосточный федеральный университет

(Владивосток)

taranenko.oi@dvfu.ru

Щепотьева Екатерина Владимировна

Старший преподаватель, Дальневосточный федеральный университет (Владивосток) shchepoteva.ev@dvfu.ru

Аннотация: Одной из задач профессиональной подготовки будущего специалиста в высшей школе является формирование человека как активной, самоорганизованной личности. Было проанализировано значение самоконтроля и самооценки как составляющих самоорганизации учебной деятельности студентов Инженерной школы Дальневосточного федерального университета. Рассмотрены теоретические аспекты самоконтроля и связанной с ним самооценки, пути формирования самооценки в условиях учебной деятельности современной школы, роли педагогической оценки и важность процесса оценивания в целом. Исследованы место самооценки учебной деятельности студентов и соотнесение ее с оценкой, данной преподавателем или одногруппниками, отношение студентов к педагогической оценке, соответствие результатов учебной деятельности студентов их возможностям, мотивы самооценки.

В заключении сделан вывод о том, что создание условий для проявления самостоятельности студентов, вооружение их рациональными приемами усвоения знаний, действиями самоконтроля и самооценки, едиными критериями оценки знаний, умений и навыков, будут эффективно воздействовать на развитие у обучающихся навыков самоорганизации и в целом активизировать их учебную деятельность.

Ключевые слова: высшая школа, процесс обучения, учебно-познавательная деятельность, личность, самоорганизация, самоконтроль самооценка, педагогическая оценка.

В определенном смысле педагогическую оценку и педагогический контроль можно считать формой внешнего социального контроля, идущего от требований будущей профессии и детерминации психического развития человека. В условиях самоорганизации учебной деятельности действия педагогического контроля и педагогической оценки переходят на уровень самоконтроля и самооценки.

Проблеме самоконтроля и самооценки, путям формирования самооценки в условиях учебной деятельности, взаимосвязи самооценки с процессом формирования и развития личности обучающегося, посвящены многочисленные исследования отечественных и зару- 
бежных ученых (Б.Г. Ананьев, Ш.А. Амоношвили, Е.И. Савонько, В.П. Левкович, А.И. Липкина, А.К. Маркова, Л.А. Рыбак и другие).

Понятия «отметка» и «оценка» играют огромное роль в педагогическом процессе. Часто эти понятия отождествляются, хотя каждое из них имеет свою смысловую нагрузку. Отношение преподавателя к процессу деятельности обучающегося, которое может выражаться как в невербальных видах общения (жесты, покачивание головы, улыбка, интонация), так и в вербальных (размышление, пояснение, высказывание), трактуют как «оценка». «Отметка» же является знаком, мерой, символом и имеет цифровое, буквенное или иное выражение.

Оценивание обучающихся по-прежнему является важной, значимой проблемой в процессе образования. Без оценивания невозможно организовать ни одну деятельность, тем более учебно-познавательную. Это продиктовано тем, что именно процесс оценивания является показателем эффективности, регулятором, одним из компонентов рассматриваемой деятельности. Оценивание следует рассматривать как часть системы контроля качества образования [3:35]. Оценивание - это инструмент, позволяющий определить развитие, прогресс не только преподавательской деятельности, но и учебнопознавательной деятельности обучающихся [3:35]. Оценивание - это способ коррекции деятельности обучаемых, с помощью которого учитель определяет уровень подготовленности ученика [4:34]. Исходя из этих утверждений, учитывая количественные и качественные показатели работы обучающихся, оценивание можно рассматривать как процесс, а оценку как его результат. Чаще всего качественные показатели проявляются в таких оценочных понятиях как «отлично», «хорошо» и т.д., а количественные показатели в баллах.

Рассматривая педагогическую оценку с точки зрения психологии, ее стимулирующая функция занимает лидирующее место, так как именно она влияет на психическое и интеллектуальное развитие обучающегося. В работах многих исследователей (А.И. Липкина, Л.А. Рыбак и др.) подчеркивается стимулирующая роль положительной отметки, которая реализуется по двум направлениям: содержанию учебного предмета и системе оценок преподавателя, при этом внешнюю оценку считают важнейшим фактором формирования самооценки обучающегося. Исследователи Л.В. Занков, Н.Д. Левитов, Е.И. Перовский определяют возможные причины необъективности педагогической оценки. Одна из важных причин субъективизма преподавателя - это отсутствие объективного текущего контроля успеваемости обучающихся в необходимом объеме.

Мы можем добиться объективности и тем самым предупредить формальное, а иногда и негативное отно- шение студентов к оценке преподавателя, при условии разработки критериев, которые будут универсальные, подходящие для многих видов работ и, которые при необходимости можно детализировать, конкретизировать, заменять, исходя из целей, задач, содержания, характера работ и потребностей студентов. Единообразие, простота, надежность, открытость должны стать основными требованиями к разрабатываемым критериям оценивания. Только в этом случае, в процессе реализации воспитательной функции создаются условия для формирования тех качеств личности, которые становятся стимулом положительного отношения к учению и далее кжеланию и потребности студентов осуществлять самоконтроль.

Вполне очевидно, что учебный самоконтроль обучающихся тесно связан с самооценкой знаний. Самооценка предполагает определение и выражение обучающимися в баллах или оценочных суждениях степени совпадения или расхождения имеющегося у них уровня знаний, умений и навыков с эталонным уровнем. [5:215]

Самооценка, самоконтроль и коррекция поведения всегда остаются взаимосвязанными процессами. Поведение не может быть саморегулирующимся без самооценки обучающимся тех действий, которые он совершает, и тех его психических свойств, которые в этих действиях проявляются.

Мы поставили цель проанализировать уровень самооценки учебной деятельности студентов 3 курса, обучающихся по программе бакалавриата в Инженерной школе Дальневосточного федерального университета (ИШ ДВФУ). Основным методом, при помощи которого мы получены данные, было анкетирование, но они также дополнялись наблюдениями за студентами и беседами с ними, посещением и анализом занятий по различным учебным дисциплинам. Всего было опрошено 120 студентов.

В таблице 1 отражены данные, которые мы получили, выявляя соотношение результатов учебной активности студентов их действительным возможностям.

Таблица 1

Соотношение возможностей результатам учебной активности студентов (по самооценке)

\begin{tabular}{|l|c|}
\hline Варианты ответов & Студенты 3 курса ИШ ДВФУ \\
\hline $\begin{array}{l}\text { 1. Результаты учебной активности соот- } \\
\text { ветствуют возможностям }\end{array}$ & $44 \%$ \\
\hline $\begin{array}{l}\text { 2. Результаты учебной активности не со0т- } \\
\text { ветствуют возможностям }\end{array}$ & $56 \%$ \\
\hline
\end{tabular}

Из таблицы 1 мы видим, что меньше половины респондентов указывают, что результаты, которые они достигают в своей учебной деятельности совпадают с их возможностями, а следовательно, больше половины обучающихся не реализуют свои возможности во время 
учебной деятельности и учебного процесса. Исходя из этих данных, мы можем предположить, что больше, чем половина студентов завышает свою самооценку, т.к. они считают свои потенциальные возможности более значительными по сравнению с достигаемыми результатами.

Чтобы выявить отношение студентов к педагогической оценке, мы попросили их ответить на следующий вопрос: «Соответствуют ли оценки, которые Вы получаете по разным предметам, действительному (реальному) уровню Ваших знаний?». Получив результаты, мы видим, что в целом студенты признают оценивание их преподавателями частично правильным или правильным, но 2\% считают, что их знания оцениваются вообще некорректно и необъективно.

Таблица 2

Соответствие оценок преподавателя самооценкам студентов

\begin{tabular}{|l|c|}
\hline \multicolumn{1}{|c|}{ Варианты ответов } & Студенты 3 курса ИШ ДВФУ \\
\hline 1. Соответствуют & $28 \%$ \\
\hline 2. Не соответствуют & $2 \%$ \\
\hline 3. Соответствуют частично & $70 \%$ \\
\hline
\end{tabular}

С другой стороны, данные, полученные в результате анкетирования, убеждают нас в том, что большинство студентов имеет собственное суждение об уровне своих знаний, достижений в учебной деятельности, но, к сожалению, их оценка не совпадает с педагогической оценкой.

Мы разделяем мнение Е.П. Бочаровой о том, что различные критерии оценивания учебной деятельности преподавателями и студентами являются главной причиной неадекватности педагогической оценки и самооценки студентов [2:29].

Посещение и анализ учебных занятий, беседы со студентами свидетельствуют в пользу того, что очень немногие преподаватели стараются комментировать ответы студентов, привлекать их к оцениванию своих ответов, сопоставлять, сравнивать получаемые результаты. Оценки за выполненные самостоятельные работы, устные ответы часто оглашаются без соответствующего анализа, а иногда вообще не объявляются студентам.

Опираясь на исследования Б.Г. Ананьева и наш собственный опыт, мы можем подтвердить, что привлечение студентов к оцениванию ответов своих одногруппников и самооценке, а также объективная оценка ответов педагогами оказывает значительное влияние на формирование объективной самооценки. По мнению Б.Г. Ананьева, многостороннее осознание обучающимися собственных знаний в большинстве своем недостаточно развито. Исследователь объясняет это рядом причин, при этом наиболее значимой из них, он считает уровень ориентационного содержания оценки на занятии, степень мотивированности, конкретности, индивидуальной направленности [1:237].

Далее представим подтверждение факта, что большинство студентов имеет собственное мнение об уровне своих знаний и своей учебной деятельности. Полученные данные от респондентов на другой вопрос анкеты: « Чье мнение о соответствии Ваших возможностей результатам учебной деятельности более верно?» представлены в таблице 3.

Таблица 3

Показатель соответствия результатов учебной активности возможностям студентов

\begin{tabular}{|l|c|}
\hline \multicolumn{1}{|c|}{ Варианты ответов } & Студенты 3 курса ИШ ДВФУ \\
\hline 1. Мнение преподавателя & $21 \%$ \\
\hline 2. Мнение одногруппников & $1 \%$ \\
\hline 3. Собственное мнение & $78 \%$ \\
\hline
\end{tabular}

Данные таблицы 3 показывают, что большинство респондентов (78\%) искренне полагают, что уровень их учебной активности более верно оценивают они сами, а не преподаватель[6:83].

Выясняя позицию студентов относительно внешней оценки (со стороны преподавателя), респондентам предложили такой вопрос: «Как Вы соотносите оценки по разным дисциплинам с собственной оценкой?» и были получены следующие результаты.

Таблица 4

Студенты о педагогической оценке

\begin{tabular}{|l|c|}
\hline \multicolumn{1}{|c|}{ Варианты ответов } & Студенты 3 курса ИШ ДВФУ \\
\hline 1. Не возражаю & $45 \%$ \\
\hline 2. Возражаю & $10 \%$ \\
\hline 3. Не обращаю внимание & $45 \%$ \\
\hline
\end{tabular}

Результаты, полученные по данной анкете, говорят о том, что респонденты в целом не возражают оценке, данной преподавателем (45\%). Но если мы сравним эту оценку с самооценкой, мы видим расхождение. Однако $10 \%$ респондентов возражают относительно полученного результата, а 45\% респондентов не волнуются за достигнутые результаты. По мнению студентов, они сами имеют представление о своих знаниях, но чтобы избежать споров с преподавателем, студенты не возражают его внешней оценке. Вслед за исследованиями А.И. Липкиной, Л.А. Рыбак наше исследование подтверждает мнение о том, что студенты все-таки интересуются оценкой, так как она побуждает к серьезной работе [6:84].

Чтобы прояснить ситуацию, когда студенты не равнодушны к оценке (довольны или нет), нам помог следую- 
щий опрос.

Таблица 5

Чем Вы руководствуетесь при оценивании Ваших учебных

\begin{tabular}{|l|c|}
\hline \multicolumn{1}{|c|}{ Варианты ответов } & Студенты 3 курса ИШ ДВФУ \\
\hline 1. Ваша самооценка & $12 \%$ \\
\hline 2. Оценка одногруппников & $8 \%$ \\
\hline 3. Учитываю все оценки & $80 \%$ \\
\hline
\end{tabular}

Студенты уверены в правильной оценке своих учебных результатов но, тем не менее, и внешнюю оценку (оценка преподавателя, одногруппника и др.) они принимают в расчёт.

А.И. Липкина, Л.А. Рыбак отмечают важность соотнесения оценки учебной деятельности студентов с позицией внешнего оценивания (оценивания другими для создания у студентов адекватной самооценки полученных результатов учебного труда) [6:85].

Беседуя с респондентами, мы стремились выяснить правильность оценки и оценивания в целом. Студенты признавались, что в определенных ситуациях оценка может радовать или наоборот их огорчать. Оценка преподавателя придает силы, направляет на дальнейшую эффективную работу, если она правильная. Однако если оценка не объясняется преподавателем или не соответствует действительности - это расстраивает студентов. Чтобы выяснить, что именно расстраивает их, мы предложили студентам ответить на такие вопросы.

Полученные результаты свидетельствует о том, что 69\% респондентов считают, что затраты труда неразде- лимы с его результатами. Студентов радует то, что оценка получена в результате приложенных стараний. Исследованиями Б.Г. Ананьева, А.В. Захаровой и др. показано, что студенты не против завышенной хорошей оценки, но опротестовывают заниженную оценку своего труда.

Таблица 6

Составляющие самооценки учебной активности

\begin{tabular}{|l|c|}
\hline \multicolumn{1}{|c|}{ Составляющие самооценки } & Студенты 3 курса ИШ ДВФУ \\
\hline 1. Затраты труда & $11 \%$ \\
\hline 2. Результат труда & $20 \%$ \\
\hline 3. Обе составляющие & $69 \%$ \\
\hline
\end{tabular}

Полученные данные позволяют отметить, что большая часть респондентов имеет завышенную самооценку своего учебного труда, а главную причину этого несоответствия они видят в несовершенстве учебной самоорганизации.

Собранные результаты подтверждают вывод о том, что в процессе работы со студентами преподавателю необходимо использовать соответствующие методы учебной работы, создавать ситуации для проявления студентами самостоятельности, привлекать их к самооценочной активности, комментировать учебную деятельность студентов. Такая работа будет стимулировать развитие и совершенствование навыков самоорганизации студентов и их учебную активность в целом. Процесс обучения будет эффективным только тогда, когда учебный труд регулярно, сознательно и объективно проверяется и контролируется, при этом студенты активно привлекаются к подобной работе и наглядно видят результаты своего труда.

\section{ЛИТЕРАТУРА}

1. Ананьев Б.Г. Избранные психологические труды. Т.2.-М.: Педагогика, 1980. - 286 с.

2. Бочарова Е.П., Тараненко 0.И. Контроль качества подготовки будущего специалиста. Сб.материалов «Акмеология - 2003». - СПб.: Санкт-Петербургская Акмеологическая Академия, 2003.- С.21-30

3. Ксензова Л.Ю. Оценочная деятельность учителя/Ю.Л.Ксензова - М.,2000 - С.35

4. Селевко Г.К. Опыт системного анализа современных педагогических систем/ Г.К. Селевко //Школьные технологии - 1996. - №6 - С.34

5. Тараненко 0.И., Федько Л.А. Самостоятельная работа будущего специалиста - путь к профессионализму. Сборник статей Международной научно практической конференции «Традиционная и инновационная наука: история, современное состояние, перспективы», 28 марта 2017 г., Екатеринбург - Изд-во: МЦИИ «Омега Сайнс», $2017-$ - С.214-217

6. Федько Л.А. Формирование основ профессионального мастерства у будущих специалистов средствами обучения самоконтролю знаний. Дисс. .... канд. пед.наук. - М., 2002. -217 с

\footnotetext{
( Ф Федько Людмила Александровна (fedko.la@dvfu.ru), Тараненко Ольга Ивановна (taranenko.oi@dvfu.ru), Щепотьева Екатерина Владимировна (shchepoteva.ev@dvfu.ru).

Журнал «Современная наука: актуальные проблемы теории и практики»
} 